\title{
Regulation and function of the JNK subgroup of MAP kinases
}

\author{
Audrey Minden ${ }^{\mathrm{a}, *}$, Michael Karin ${ }^{\mathrm{b}}$ \\ ${ }^{a}$ Columbia University, Biological Sciences Department, 2460, 813 Fairchild, 1212 Amsterdam Avenue, New York, NY 10027, USA \\ ${ }^{\mathrm{b}}$ Department of Pharmacology Program in Biomedical Sciences UCSD School of Medicine 9500 Gilman Drive La Jolla, CA \\ 92093-0636, USA
}

Received 27 May 1997; accepted 27 May 1997

\section{Contents}

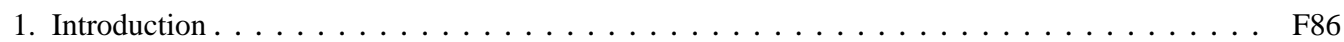

2. Signal transduction pathways leading to activation of MAP kinases in yeast $\ldots \ldots \ldots$. . . F87

3. Signal transduction pathways leading to activation of the ERK MAP kinase pathways in

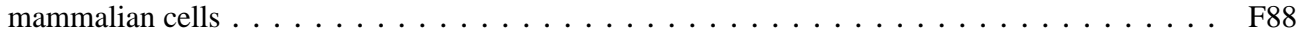

4. Signaling pathways leading to activation of the JNK MAP kinases. . . . . . . . . . . . . . F89

4.1. Activation of the JNK pathway by extracellular stimuli . . . . . . . . . . . . . . . . F89

4.2. Small GTP binding proteins in the JNK pathway . . . . . . . . . . . . . . . F89

4.3. MAPKKKs and MAPKKs in the JNK pathway. . . . . . . . . . . . . . F F90

4.4. Mammalian STE20 homologues and related proteins in the JNK pathway . . . . . . . . . F90

4.5. Potential role for phosphoinositide-3-kinase in the JNK pathway . . . . . . . . . . . F F91

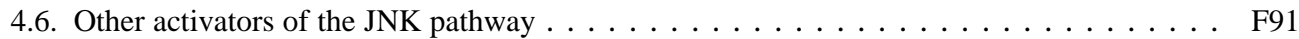

5. Signaling pathways leading to activation of the P38 MAP kinase . . . . . . . . . . . . F92

6. Downstream targets of the JNK pathway. . . . . . . . . . . . . . . . . . . F92

6.1. The activity of transcription factor $\mathrm{C}$-jun is regulated by phosphorylation . . . . . . . . F92

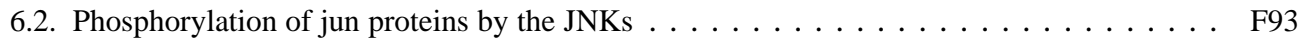

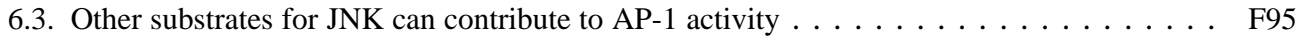

7. Downstream targets of the P38 and ERK pathways also contribute to AP-1 activity . . . . . . F96

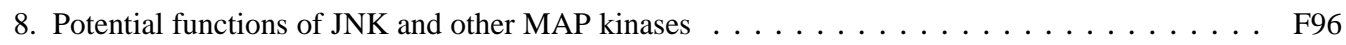

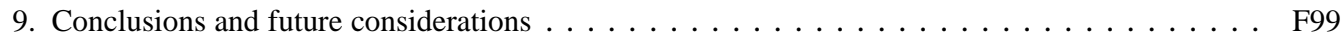

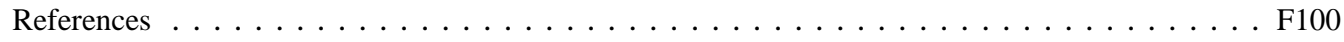

\footnotetext{
* Corresponding author. Fax: +1 212 8658246; E-mail: agm24@ columbia.edu 


\section{Introduction}

Mammalian cells respond to extracellular stimuli by activating signaling cascades that are mediated by members of the MAP kinase family. MAP kinases act by phosphorylating various substrates including transcription factors. These in turn regulate expression of specific sets of genes and thus can mediate a specific genetic response to the stimulus. The basic organization of signaling pathways leading to MAP kinase activation is highly conserved from yeast to mammalian cells. Several subgroups of MAP kinases were identified in mammalian cells, which differ in their substrate specificities and regulation. Members of the JNK subgroup of MAP kinases are activated in response to diverse extracellular stimuli, including UV irradiation, proinflammatory cytokines and certain mitogens. The JNKs phosphorylate specific sites on the amino terminal trans-activation domain of transcription factor c-Jun, an important component of transcriptional activator AP-1. Phosphorylation of these sites stimulates the ability of c-Jun to activate transcription of specific target genes. In addition to c-Jun, the JNKs phosphorylate and activate several other transcription factors, most of which can contribute to AP-1 activity. This review provides an overview of MAP kinase activation, with particular emphasis on the signal transduction pathways leading to activation of the JNK subgroup of MAP kinases. We also discuss the regulation of AP-1 activity by JNK and other MAP Kinases, as well as the possible functions of JNK activation.

In order to survive and develop normally, eukaryotic cells must be able to respond to a diverse array of extracellular stimuli and adapt to adverse conditions. In many cases cells respond to extracellular stimuli and environmental stresses by adjusting their responses to other stimuli, and by adjusting their gene expression programs. Exposure to certain extracellular stimuli can trigger cell growth and division, while exposure to other stimuli can induce cell differentiation or even programmed cell death. Exposure to environmental stresses results in activation of various stress responses which help the cells withstand adverse environmental conditions. An intriguing question is how external stimuli that signal through cell surface receptors, elicit changes in cell phenotype and morphology. One common way for executing such responses is by turning on cascades of biochemical events in response to receptor activation which transmit information from the cell surface to the transcriptional machinery in the nucleus. By modulating the activities of sequence specific transcription factors and combinations thereof, extracellular stimuli activate or repress the expression of specific sets of genes. The products of such genes are the ultimate mediators of the phenotypic responses. It is important to elucidate the components of these signal transduction pathways and the mechanisms that govern the transmission of information. In addition to understanding how normal cells respond to extracellular stimuli, such information will help in deciphering what goes wrong in a variety of clinical disorders. In diseases such as cancer or diabetes, for example, cells fail to respond properly to extracellular stimuli, resulting in loss of normal growth control or improper regulation of energy metabolism.

Among the major types of signal transduction pathways in eukaryotic cells are protein kinase cascades which culminate in activation of a family of protein kinases known as mitogen activated protein kinases, or MAP kinases [1-4]. Although they vary in their substrate specificities and responses to extracellular stimuli, MAP kinases are highly conserved in their primary structure and mode of activation (see Fig. 1). All eukaryotes that have been examined contain several types of MAP kinases which function in the transmission of signals from cell surface receptors to transcription factors and other cellular targets. All MAP kinases are serine/threonine kinases that are activated in response to their phosphorylation on invariant threonine and tyrosine residues, within a TXY motif, by dual specificity MAP kinase kinases (MAPKKs). The MAPKKs also form a highly conserved group that are activated through phosphorylation of conserved serine and threonine residues by a somewhat more diverse group of MAP kinase kinase kinases (MAPKKKs). The latter group receives signals from cell surface receptors through a variety of intermediates, including other protein kinases and small GTP binding proteins. In the different MAP kinase pathways the MAPK, MAPKK, and MAPKKKs are usually highly conserved in their catalytic domains, but can differ considerably in their regulatory domains and their substrate specificities.

The first mammalian MAP kinase cascade to be 


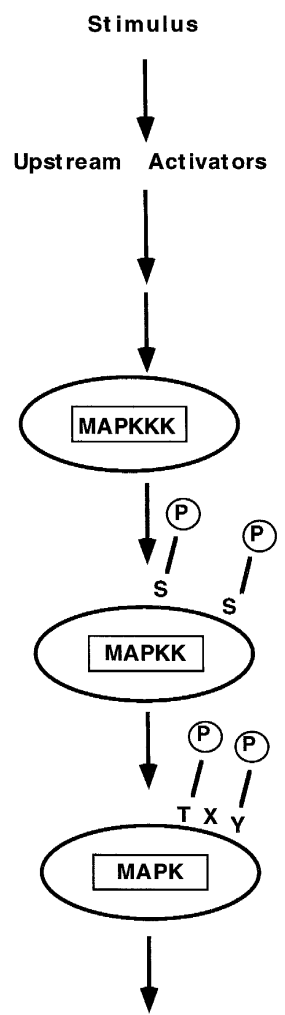

Fig. 1. MAP Kinases are generally activated by a conserved type of signaling pathway. MAP Kinases are activated by phosphorylation on threonine and tyrosine residues by dual specificity MAP Kinase Kinases. MAP Kinase Kinases comprise a conserved group that are activated by phosphorylation on conserved serine and/or threonine residues, by MAP Kinase Kinase Kinases. This latter group of kinases are regulated by other protein kinases and GTP binding proteins in response to a stimulus.

characterized in detail was the pathway leading to activation of the Extracellular Signal Regulated Kinase (ERK) subgroup of MAP kinases [5]. Recently, a great deal of effort has gone into characterization of the signaling pathways that lead to activation of another mammalian MAP kinase cascade, the one which impinges on the Jun Kinases (JNKs) also known as stress-activated protein kinases (SAPKs) [6-8]. The JNKs were first identified by their ability to phosphorylate specific sites on the amino terminal transactivation domain of the transcription factor cJun following exposure to UV irradiation, growth factors, cytokines, or expression of transforming oncogenes [6,7]. By phosphorylating these sites, the JNKs stimulate the ability of c-Jun to activate transcription of target genes. More recently, a third sub- group of mammalian MAP kinases, collectively known as p38 or Mpk2, was identified $[9,10]$. The regulation of p38 activity is similar to that of JNK activity [10]. However, the p38 subgroup does not phosphorylate the activation domain of c-Jun and thus differs from JNK in their substrate specificity and possibly function. Finally, other mammalian MAP Kinases that have recently been identified include ERK3 [11], ERK5 [12], and several p38 related kinases [13-16]. The regulation and functions of these latter MAP Kinases have not yet been elucidated.

\section{Signal transduction pathways leading to activa- tion of MAP kinases in yeast}

Prior to the identification of MAP kinases in mammalian cells, mating pheromone responsive MAP kinases were identified and studied in yeast [17]. This provided an important genetic basis for understanding how MAP kinases are regulated in other organisms including mammals. In the budding yeast Saccharomyces cerevisiae, several signaling cascades lead to activation of different MAP kinases which mediate distinct biological responses ([18] and Fig. 2). These include the MAP kinase cascade that is triggered when haploid yeast respond to mating pheromones [19], a MAP kinase cascade that is necessary for maintenance of cell wall integrity [20], and a MAP kinase cascade that is triggered by osmotic stress [21]. All of these cascades are distinct and are mediated by different MAP kinases. As these cascades lead to distinct biological responses, the MAP kinases found at their output must phosphorylate different substrates. These include different transcription factors that control distinct sets of target genes. Despite the differences in their responses to upstream stimuli, all of these MAP kinase cascades are organized in a similar fashion, consisting of MAPKKK-MAPKKMAPK, where MAPKKK is activated by other kinases and GTP binding proteins. Recently, the pheromone responsive MAP kinase cascade was found to be organized by a scaffolding protein, STE5, which is necessary for its proper function [22]. By having separate binding sites for the MAPK, MAPKK and MAPKKK, STE5 organizes the components of the pathway into a functional module allowing their efficient activation [22], and insulates them from 
YEAST

$\begin{array}{ll}\text { Cell Wall } & \text { Mating/ } \\ \text { Integrity } & \text { Osmotic Stress }\end{array}$

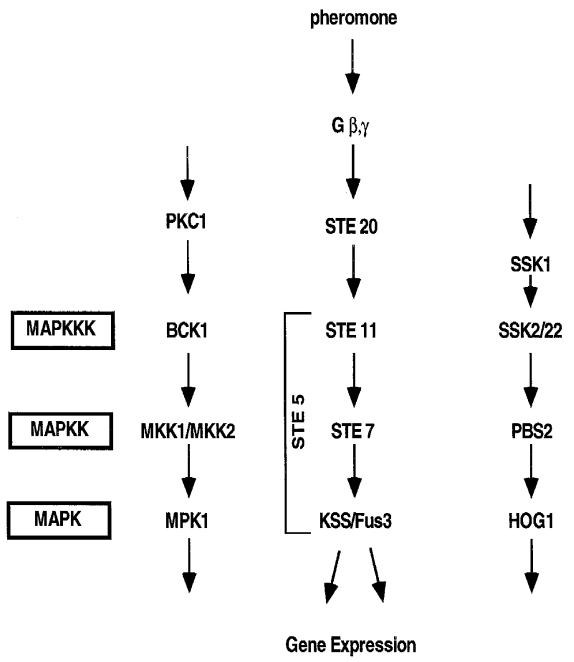

Fig. 2. At least five different MAP Kinase pathways have been studied in yeast. Three of them are outlined here. While they all mediate different types of responses, the different MAP Kinases are regulated by a similar mechanism.

components of other modules [22]. STE5 was also shown to physically interact with the different GTP binding proteins that affect this cascade [23], as well as an upstream protein kinase STE20 [24,25]. Although the organization of the different components into a tightly linked module greatly enhances the specificity of the cascade, such an organization is a hindrance to signal amplification.

\section{Signal transduction pathways leading to activa- tion of the ERK MAP kinase pathways in mam- malian cells}

Studies of mammalian MAP kinase cascades have revealed a striking evolutionary conservation from yeast to mammals. The signaling pathway leading to ERK activation, illustrated in Fig. 3, was the first MAP kinase pathway to be studied in mammalian cells. The ERK subgroup of MAP kinases is activated most potently by mitogenic stimuli such as growth factors. Most commonly, the pathway leading to
ERK activation begins when growth factors bind to cell surface receptors with intrinsic tyrosine kinase activity [26]. Ligand induced receptor clustering results in autophosphorylation of the receptor cytoplasmic domain on tyrosine residues. This is followed by the recruitment of $\mathrm{SH} 2$ domain containing adaptor proteins such as GRB2 or SHC to the activated receptor. This results in the recruitment of additional proteins to the activated receptor complex [27]. The recruitment of the exchange factor Sos, places it in the membrane next to its substrate, the small GTP binding protein Ha-Ras [28]. Sos activates Ha-Ras by catalyzing GDP:GTP exchange [29,30]. Once Ha-Ras is activated it binds and recruits the serine/threonine kinase Raf-1 to the membrane [31]. While membrane translocation of Raf-1 is essential for its activation, it is not sufficient. A second step, leading to Raf-1

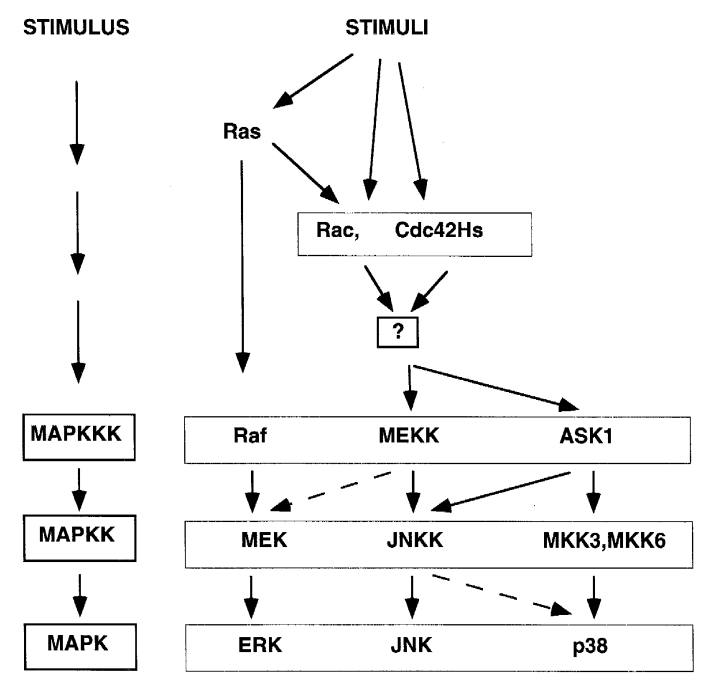

Fig. 3. ERKs are activated by a variety of stimuli including the phorbol ester TPA, and growth factors such as EGF, NGF, and PDGF. JNK is also activated by growth factors, as well as by other stimuli including TNF $\alpha$, IL-1, osmotic stress, UV irradiation, and various stimuli that activate heterotrimeric $G$ protein coupled receptors. p38, which was identified as a kinase that is activated by lipopolysaccharide (LPS), is activated by many of the stimuli that activate JNK. JNK is activated by both Ha-Ras dependent pathways in response to growth factors such as EGF, and by Ha-Ras independent pathways in response to the cytokines TNF $\alpha$ and IL-1. While some stimuli operate through Rac or $\mathrm{Cdc} 42 \mathrm{Hs}$, other may operate by $\mathrm{Rac} / \mathrm{Cdc} 42 \mathrm{Hs}$ independent mechanisms. Finally, a number of other signaling enzyme have been identified, which can activate the ERK, JNK, and p38 pathways. Some of these signaling enzymes are described in the text, but are not illustrated here. 
phosphorylation, is also required [32]. Raf-1 functions as the MAPKKK in the ERK cascade, although by sequence it is not a classical MAPKKK. Once Raf- 1 is activated it phosphorylates and activates the MAPKKs, MEK1 and MEK2 [33,34]. While Raf is the most well characterized MAPKKK in the ERK pathway, other MAPKKKs such as the Mos protooncogene, can also activate the MEKs. The mode of regulation of Mos however, is not yet clearly defined [35-37]. Once activated, either MEK1 or MEK2 can directly activate the ERKs (consisting of ERK1 and ERK2) by phosphorylating their conserved threonine and tyrosine activation sites [38]. Once the ERKs are activated a fraction of the enzyme translocates to the nucleus where they phosphorylate and thereby regulate transcription factors which mediate changes in gene expression [39]. The mechanism responsible for nuclear translocation of activated ERK is still unknown. It is possible, however, that nuclear entry occurs by passive diffusion and that physical association with upstream components of their activation cascades excludes the inactive form of MAP kinase from the nucleus and other subcellular locals. Transcription factors whose activities are regulated by ERK mediated phosphorylation include various members of the TCF family, such as Elk1 [39-42] and SAP1 [43]. Other targets include Ets1 and Ets2 [44,45], and CREB, whose phosphorylation is activated by the ERK activated protein kinase RSK2 [46].

\section{Signaling pathways leading to activation of the JNK MAP kinases:}

\subsection{Activation of the JNK pathway by extracellular stimuli}

The signaling pathway leading to JNK activation (see Fig. 3) was the first mammalian MAP kinase pathway to be investigated as thoroughly as the ERK pathway. In fact it was the first demonstration that different types of MAP kinase cascades operate in mammalian cells. Although it contains the conserved features of classical MAP kinase cascades, the JNK pathway is distinct from the pathway that activates the ERKs. The JNK family of MAP Kinases are activated by a variety of different types of cellular stresses as well as extracellular stimuli. Like the ERKs, JNK can be activated by growth factors such as Epidermal Growth Factor (EGF) and Nerve Growth Factor (NGF). In addition, JNK is strongly activated by cytokines such as Tumor Necrosis Factor a (TNF $\alpha)$ and Interleukin-1 (IL-1) [47-49]. As described above, signaling by growth factors starts with ligand induced receptor auto-phosphorylation on tyrosine. Unlike growth factor receptors, cytokine receptors do not have tyrosine kinase activity. In the case of $\mathrm{TNF} \alpha$, activation of downstream signaling events is mediated by a family of TNF $\alpha$ receptor interacting proteins that are recruited following ligand induced receptor trimerization [50]. Binding of two proteins, TRAF2 and RIP to the TNF receptor 1 (TNFR1) for example, are thought to trigger the events that lead to the JNK activation cascade [51,52].

\subsection{Small GTP binding proteins in the JNK pathway}

Once cells surface receptors are activated, the signaling pathway leading to JNK activation is initiated. This signaling pathway differs from the one leading to ERK activation. Unlike the ERKs, the JNKs are activated by two Ha-Ras related GTP binding proteins of the Rho family, namely Rac (both Rac-1 and Rac-2) and Cdc42Hs [53-56]. These small GTP binding proteins were until recently known mostly for their roles in controlling the organization of the actin cytoskeleton [57-59]. Rac mediates actin polymerization into lamellipodia or membrane ruffles in response to growth factors and Ha-Ras activation [57], while over-expression of activated $\mathrm{Cdc} 42 \mathrm{Hs}$ induces filopodia formation [58,59]. The finding that these GTP binding proteins also activate the JNK pathway indicated that they are also involved in transmitting signals from membrane receptors to the nucleus and regulating gene expression. While Rac and $\mathrm{Cdc} 42 \mathrm{Hs}$ both activate the JNK MAP kinase cascade, so far they have not been shown to be involved in activation of the ERK pathway [53-56]. A dominant inhibitory mutant of Rac blocks JNK activation by Ha-Ras, as well as by growth factors such as EGF, and by nonreceptor tyrosine kinases such as v-Src[53,54]. While over-expression of dominant inhibitory Rac can block JNK activation by 
cytokines such as TNF $\alpha$ and IL-1 [54], lower doses preferentially block JNK activation by growth factors but not TNF $\alpha$ ([53] and Liu and Karin, unpublished data). Similarly, a dominant inhibitory Ha-Ras mutant blocks growth factor activation of JNK but does not effectively block TNF $\alpha$ or IL- 1 activation of JNK $[60,61]$. These results suggest that while growth factor and $\mathrm{v}-\mathrm{Src}$ activation of JNK are mediated by Ha-Ras and Rac, TNF $\alpha$ and IL-1 activation of JNK may be primarily independent of Ha-Ras and Rac. It is not yet clear how Cdc42Hs fits into the pathway. Cdc42Hs may activate Rac, leading to Rac dependent signaling events $[58,59]$. Some workers suggested that $\mathrm{Cdc} 42 \mathrm{Hs}$ may respond to Ha-Ras-independent stimuli [58]. One possibility is that $\mathrm{Cdc} 42 \mathrm{Hs}$ responds to stimuli such as TNF $\alpha$, that lead to JNK activation. However, $\mathrm{TNF} \alpha$ does not induce fillopodia and lamelipodia formation, the hallmarks of $\mathrm{Cdc} 42 \mathrm{Hs}$ and Rac activation (Z.G. Liu, J. Feramisco and M. Karin, unpublished results).

\subsection{MAPKKKs and MAPKKs in the JNK pathway}

The MAPKKKs in the JNK pathway differ from those in the ERK pathway. While Raf is critical for ERK activation in response to Ha-Ras [33,34], Raf does not have any direct role in the JNK activation pathway [60]. Instead, another MAPKKK, MEKK-1, leads to JNK activation $[60,62]$. The mechanism that controls MEKK1 activity in response to Ras activation or other inputs such as EGF or TNF $\alpha$ is not known, nor is it clear whether such inputs actually stimulate MEKK1 catalytic activity. Unlike Raf, MEKK1 isolated from non-stimulated cells is constitutively active ([63] and Y. Xia and M. Karin, unpublished results). Furthermore, expression of wild type MEKK1 is sufficient for JNK activation ([63] and B. $\mathrm{Su}, \mathrm{Y}$. Xia and M. Karin, unpublished). This suggests that MEKK by itself may be constitutively active. This raises the possibility that extracellular stimuli such as growth factors and cytokines could trigger events that lead to the sequestration of an MEKK inhibitor in the cell, rather than stimulating its activity directly. Although MEKK1 was identified as a protein kinase that phosphorylates MEK [64], MEKK1 is an inefficient activator of the ERK pathway [60]. MEKK1 and the related MEKK2 and MEKK3 [65] are similar in sequence to the yeast MAPKKK, STE11 [64] (see Fig. 2). Like STE11, MEKK1 functions as a MAPKKK in the JNK pathway [60]. MEKK2 and 3 can also activate the JNK cascade [65] although MEKK3 preferentially activates the ERK cascade [65]. In addition to the MEKKs, another serine/threonine kinase, Tpl2, shares sequence identity with STE11, and can activate both the JNK and the ERK pathways [66].

The effects of MEKK or Tpl2 on JNK activity are mediated by the JNK activating kinase JNKK1, also known as SEK1 or MKK4 [67-69]. JNKK1 was shown to be activated by MEKK1 through phosphorylation at serine and threonine residues [67]. Once activated, JNKK1 directly phosphorylates JNK on threonine and tyrosine, the conserved MAP kinase activation sites $[62,67]$. JNKK thus functions as the MAPKK in the JNK pathway. Interestingly, like MEKK, JNKK is a homologue of a yeast signaling enzyme. JNKK1 is structurally and functionally homologous to the yeast MAPKK PBS2, which functions in the hyperosmolarity responsive MAP kinase cascade leading to activation of the HOG1 MAP kinase $[21,70]$. JNKK1 can partially substitute for PBS2 in yeast [67]. Consistent with this, JNK can partially substitute for HOG1, and is activated by PBS2 upon exposure of yeast cells to hyperosmolarity ([71], and A. Lin and M. Karin, unpublished).

\subsection{Mammalian STE20 homologues and related pro- teins in the JNK pathway}

Results from experiments using dominant inhibitory mutants have indicated that MEKK functions downstream to Rac and Cdc42Hs. Rac and Cdc42Hs however, have not been shown to activate MEKK1 directly. It is not clear therefore, how these GTP binding proteins can activate the JNK pathway. It was suggested that the Rac-responsive serine/threonine kinase PAK, or one of its close relatives, acts between Rac and MEKK [55,72-75]. These protein kinases bind GTP-loaded Rac and $\mathrm{Cdc} 42 \mathrm{Hs}$ through a specific $\mathrm{Cdc} 42 \mathrm{Hs} / \mathrm{Rac}$ Interactive Binding (CRIB) motif, and are strongly activated by them in a GTP-dependent manner [72,73]. Human PAK1, 2 and PAK65, which are nearly identical in sequence, are the mammalian homologues of the yeast protein kinase, STE20. In S. cerevisiae, STE20 
functions upstream to STE11 in the pheromone responsive MAP kinase pathway ([17] and Fig. 2). Furthermore, the founding member of the Rho family, Cdc42Sc, originally identified by its role in bud site selection (i.e. a cytoskeletal reorganization event; [76] was recently found to be involved in activation of STE20 in the pheromone responsive MAP kinase cascade ([17,77], and Fig. 2). However, it is not clear how STE20 affects STE11 activity and, in fact, it has not even been shown to have a direct effect on STE11 activity. Considering the conservation in organization of yeast and mammalian MAP kinase cascades and the fact that PAK1, 2 and PAK65 are directly activated by $\mathrm{Rac}$ and $\mathrm{Cdc} 42 \mathrm{Hs}$, it is tempting to place them downstream of these in small GTP binding proteins in the pathway leading to JNK activation. However, although it was reported that some of the PAKs may activate JNK or p38 $[55,56,78]$, the effects were rather small and were found to be celltype dependent and mostly due to vast overexpression of these proteins (A. Minden and M. Karin, unpublished results).

Another mammalian STE20 related kinase, Germinal Center Kinase (GCK) [79], was also shown to activate the JNK pathway [80]. Unlike PAK however, GCK does not appear to be activated by Rac and $\mathrm{Cdc} 42 \mathrm{Hs}$ [80] and therefore may mediate JNK activation by Rac and $\mathrm{Cdc} 42 \mathrm{Hs}$ independent stimuli. Interestingly, GCK can be activated by $\mathrm{TNF} \alpha$, suggesting that GCK could mediate JNK activation by cytokines. Other STE20 related proteins that have been implicated in JNK activation include HPK1, NIK, and KHS [81-83]. The mode of regulation of these kinases are not yet fully understood however, and they do not appear to mediate activation by Rac and Cdc42Hs. Finally, like the PAKs, the Mixed Lineage Kinase MLK3 [84] contains a conserved CRIB motif. MLK3 (also known as SPRK), and the related kinase MUK, activate the JNK pathway, probably by direct activation of JNKK [85-88]. Thus, MLK3 and MUK can serve as MAPKKKs in the JNK pathway. Despite the presence of a CRIB motif however, the interaction of MLK3 with $\mathrm{Rac}$ and $\mathrm{Cdc} 42 \mathrm{Hs}$ is somewhat week [87]. Therefore, MLK3 and MUK may mediate JNK activation by $\mathrm{Rac} / \mathrm{Cdc} 42 \mathrm{Hs}$ independent signals, and the putative signaling enzymes that mediate $\mathrm{Rac}$ and Cdc42Hs activation of the JNK cascade remain to be identified.

\subsection{Potential role for phosphoinositide-3-kinase in the JNK pathway}

It is not yet clear how Ras may lead to Rac and $\mathrm{Cdc} 42 \mathrm{Hs}$ activation. One possibility is that the lipid kinase phosphoinositide-3-kinase (PI3 kinase) may play a role. The catalytic subunit of PI3 kinase, p110, binds to, and is activated by Ha-Ras, in a GTP dependent manner [89-91]. Recent work has suggested that overexpression of a constitutively active mutant of p110 can lead to Rac activation [92]. Taken together, these data would suggest that PI3 kinase could have a role in connecting Ha-Ras activation to Rac activation. It is not yet clear however, whether PI3 kinase is sufficient to activate the JNK pathway. In NIH3T3 cells, overexpression of constitutively active p110 was shown to be sufficient to induce lamellipodia formation, but not JNK activation [92], suggesting that PI3 kinase can stimulate only a subset of Rac's activities. On the other hand, overexpression of constitutively active p110 in Cos cells did activate JNK, suggesting that at the high level of expression obtained in these cells, PI3 kinase is sufficient to activate multiple downstream signaling events, including JNK activation [93]. More work will be required therefore, to clearly define the potential role for PI3 kinase in the JNK activation pathway.

\subsection{Other activators of the JNK pathway}

In addition to the small GTP binding proteins described above, JNK may also be activated by heterotrimeric $\mathrm{G}$ proteins. For example, certain stimuli, such as thrombin and charbacol, which activate heterotrimeric $G$ protein coupled receptors, were reported to activate JNK [94-98]. Consistent with this, constitutively active mutants of the a subunits of heterotrimeric $\mathrm{G}$ proteins $\mathrm{G} 12$ and $\mathrm{G} 13$ were shown to activate JNK by a pathway that involves Rac, MEKK1, and JNKK1 [98-100]. However, it is not clear whether and how Ga12 and Ga13 can lead to Rac activation. Other stimuli that activate the JNKs include UV irradiation, ionizing irradiation, heat shock, hyperosmolarity, and DNA damaging agents [60,71,101-105]. UV irradiation was shown to result in clustering of cell surface receptors including those for EGF, TNF $\alpha$, and IL-1 [106]. Furthermore, JNK activation by $\mathrm{UV}$ irradiation does not require a nu- 
cleus [107]. It is expected therefore, that UV irradiation activates JNK by a signaling pathway similar to the one described above, rather than by a DNA damage induced signal. It is not clear however, whether UV irradiation can signal through small GTP binding proteins such as Rac and $\mathrm{Cdc} 42 \mathrm{Hs}$.

Furthermore, UV irradiation can activate JNK even in the absence of JNKK [108], suggesting that activation of JNK by cellular stresses such as UV irradiation may require signaling enzymes other than those previously described. The non-receptor tyrosine kinase c-abl may be involved in JNK activation in response to some cellular stress. By using c-abl null cells it was shown for example, that JNK activation by ionizing radiation, alkylating agents, and the DNA damaging agent ara-C, require functional c-abl $[104,105]$. Other DNA damaging agents such as MMS however, activate JNK by a c-abl independent mechanism [109], and UV irradiation also does not seem to signal through c-abl [109]. Another signaling enzyme that may be involved in JNK activation in response to some stimuli is the tyrosine kinase Pyk2 [110]. Pyk2 seems to be a cell type specific mediator of JNK activation in response to certain stimuli such as heterotrimeric $\mathrm{G}$ protein coupled receptors, UV irradiation, $\mathrm{TNF} \alpha$, and changes in osmolarity [110]. The mechanism of action of Pyk is not known, although it may act by recruiting adapter proteins such as Grb2 and SHC [111]. Thus, different types of stimuli may activate JNK by different mechanisms, and future work will be required to identify the signaling enzymes involved in mediating JNK activation in response to various stimuli.

\section{Signaling pathways leading to activation of the P38 MAP kinase}

A third mammalian MAP kinase pathway leads to p38 activation (see Fig. 3). p38 was originally identified as a kinase that is activated by Lipopolysaccharide (LPS) $[9,112]$. p38 is activated many of the same extracellular stimuli that activate the JNKs [113]. p38 is the structural homologue of yeast Hog1 [9], and like JNK, can partially substitute for Hog 1 in yeast [9]. Like the JNKs, p38 is activated by Rac and Cdc42Hs $[53,78]$. In contrast, p38 is not efficiently activated by MEKK1, 2, or 3 [65,67]. The serine threonine kinase ASK1, however, appears to be an effective MAPKKK in the p38 pathway, and can also activate the JNK pathway [114]. p38 can be directly activated by JNKK [67-69], and also by two other MAPKKs, MKK3 and MKK6 [69,115,116].

\section{Downstream targets of the JNK pathway}

\subsection{The activity of transcription factor $C$-jun is regulated by phosphorylation}

Once activated, JNK phosphorylates a number of targets. It was originally identified however, based on its ability to phosphorylate specific sites on the amino terminal activation domain of c-Jun. Phosphorylation of these sites dramatically stimulates c-Jun's activity as a transcription factor. c-Jun, encoded by the $c$-jun proto-oncogene, is a sequence specific transcription factor whose function has been implicated in various cellular events ranging from cell proliferation and differentiation to neoplastic transformation [117]. cJun is a component of the sequence specific transcriptional activator AP-1 [117]. AP-1 is a collection of dimers composed of the Jun, Fos or ATF families of bZIP (basic region-leucine zipper) DNA binding proteins. These dimers bind to a common cis acting element known as the TRE (TPA response element) or the AP-1 site [117]. While many of the AP-1 factors are transcriptional activators, certain AP-1 complexes can function as transcriptional repressors $[117,118]$. The exact function and potency of AP-1 complexes is determined by their composition. The composition of the AP-1 complex may also determine the specificity of target gene activation, as suggested by the distinct phenotypes observed in response to inactivation of genes encoding AP-1 components [119-121]. Part of the specificity of AP-1 complexes may be determined by interaction with other transcription factors belonging to the Ets [122] or Rel [123] families. In addition, the activity of AP-1 components is modulated by interaction with coactivator proteins, such as the Jun activation domain binding protein 1 (JAB1; [124]. In addition to c-Jun, the Jun family of protooncogenic transcription factors contains JunB [125] and JunD [126].

The abundance and activity of c-Jun are modulated in response to extracellular stimuli. Although we 
know less about the regulation of JunB and JunD, it is likely that their abundance and activities are also regulated. The amount of c-Jun is primarily regulated at the transcriptional level due to the fact that the $c$-jun gene is an immediate early gene [127]. In non-stimulated logarithmic growing cells, the amount of c-Jun is quite low, and these levels are even lower in serum-deprived quiescent cells. Like other immediate early genes, $c$-jun transcription is rapidly stimulated, independently of de novo protein synthesis, following exposure to a variety of extracellular stimuli, including growth factors, proinflammatory cytokines and UV irradiation [127-130]. This results in production of more $c$-jun mRNA and ultimately in an increase in the amount of c-Jun protein in the nucleus.

A second level of regulation occurs post-transcriptionally through c-Jun phosphorylation. Phosphorylation of sites within the $\mathrm{N}$-terminal activation domain of c-Jun, serines 63 and 73 dramatically stimulates the transcriptional activity of the protein [131-133]. In addition, phosphorylation of the same sites was suggested to increase the stability of the protein resulting in a modest increase in its steady state level [134]. Non-stimulated cells express low levels of c-Jun protein whose N-terminal sites are mostly not phosphorylated. Although the protein may be bound to certain AP-1 sites, its transcriptional activity is low. Exposure of cells to growth factors, proinflammatory cytokines, UV irradiation [47,128], or the alkylating agent methylmethane sulphonate (MMS; [109], results in a rather rapid increase in phosphorylation of serine 73 and to a lesser extent serine 63 [47]. Interestingly, the same stimuli which enhance the phosphorylation of these N-terminal sites, also cause induction of $c$-jun transcription $[47,128,129]$. This correlation supports the autoregulatory model in which transcription of the $c$-jun gene is mediated by a modified AP-1 site in its own promoter [127].

The JNK family of MAP Kinases specifically phosphorylate Serines 63 and 73 on the c-Jun activation domain, and so far they are the only MAP kinases known to phosphorylate these sites. Consistent with the role for JNK in phosphorylating and activating c-Jun, signals that activate the JNK pathway also stimulate c-Jun phosphorylation in vivo, and stimulate c-Jun transcriptional activity $[60,135]$. It is possible to construct altered specificity mutants of
c-Jun in which Serines 63 and 73 are phosphorylated by protein kinase A instead of JNK [136]. Nevertheless, phosphorylation of the two sites still stimulates the transcriptional activity of c-Jun [136]. Mutants in which Serines 63 and 73 are changed to non-phosphorylatable amino acids on the other hand, can not be activated by upstream activators [53]. Phosphorylation of the c-Jun amino terminal sites therefore seems to be critical for stimulating c-Jun's transcriptional activity. A likely mechanism underlying this transcriptional enhancement is the ability of N-terminal phosphorylated c-Jun to interact with additional coactivators such as CBP [137]. Although a formal genetic proof is still missing, the N-terminal phosphorylation of c-Jun is believed to be critical for activation of a subset of AP-1 or c-Jun target genes.

\subsection{Phosphorylation of jun proteins by the JNKs}

The use of affinity columns containing the $\mathrm{N}$ terminal activation domain of c-Jun led to identification of at least two kinase activities, 46 and $55 \mathrm{kDa}$ in size, which bind to this region of c-Jun and phosphorylate it on serines 63 and 73 [6]. Most importantly, the regulation of these activities parallels the regulation of c-Jun phosphorylation in intact cells [47]. The JNKs were also independently identified as cyclohexamide activated protein kinases and were named SAPKs $[8,137]$. Only after isolation of the corresponding DNA clones was it realized that the JNKs and SAPKs are the same [7,8]. The JNK subgroup includes the products of three related genes $J N K 1$ [7], $J N K 2$ [48,49], and $J N K 3$ [101]. Alternatively they are referred to as $\operatorname{SAPK} \alpha, \operatorname{SAPK} \beta$ and $\operatorname{SAPK} \gamma$ [8]. Each of these genes directs the production of several JNK polypeptides due to alternative splicing (K. Yoshioka and M. Karin, unpublished results and [101]). While JNK1 and JNK2 are expressed in most if not all cell types [48], expression of JNK3 appears to be limited to neuronal cells [101]. All the JNK isoforms are regulated identically in response to extracellular stimuli $[48,101]$.

Although the major products of the JNK1 and $J N K 2$ genes are identical in their responses to extracellular stimuli, they differ in their ability to phosphorylate c-Jun. Using c-Jun activation domain affinity beads it was shown that the $55 \mathrm{kDa}$ JNK2 polypeptide has a much higher affinity towards c-Jun 
than the $46 \mathrm{kDa}$ JNK1 polypeptide [48]. As a result, JNK2 is a more efficient c-Jun kinase than JNK1, having a lower $\mathrm{Km}$ and higher Vmax [48]. The two kinases are, however, identical in their ability to phosphorylate murine p53 (T. Kallunki and M. Karin, unpublished results), and it is assumed that other substrates may be more efficiently phosphorylated by JNK1. Using a series of chimeras, the differences in the ability to bind and phosphorylate c-Jun were mapped to a 23 amino acid segment that is located next to the catalytic pocket of the enzyme but is not an actual part of it [48]. Interestingly, this region is encoded by a separate exon which, in the case of the JNK2 gene, has been duplicated and is subject to alternative splicing (K. Yoshioka, T. Kallunki and M. Karin, unpublished results and [101]). Thus, the major polypeptide encoded by the JNK2 gene is an efficient c-Jun kinase, while the minor product is a low affinity c-Jun kinase similar to JNK1 (K. Yoshioka, T, Kallunki and M. Karin, unpublished results). A mutant of JNK1 in which the 23 amino acid segment is derived from JNK2 is as efficient in c-Jun phosphorylation as wild-type JNK2 [48]. This short segment of JNK present in its C-terminal lobe serves to anchor the enzyme onto a specific docking site on its substrate c-Jun, which was localized between amino acids 30 and 60 in the N-terminal activation domain of c-Jun [138]. Although JNK2 forms a very stable complex with c-Jun in vitro [48], all attempts to coprecipitate the two proteins from cells have failed (M. Hibi and M. Karin, unpublished results). The reason for this failure is two fold. First, like other MAP kinases the JNKs are excluded from the nucleus prior to activation [139]. Second, once c-Jun is phosphorylated by the activated form of JNK, which enters the nucleus [139], the c-Jun:JNK complex is destabilized [6]. Despite the failure to isolate c-Jun:JNK complexes from cells, the importance of JNK docking to c-Jun is strongly supported by mutational analysis. Mutations that abolish or decrease JNK binding to c-Jun in vitro result in a large decrease or complete inhibition of JNK-mediated cJun phosphorylation in intact cells [138].

The interaction of JNK with c-Jun is bipartite. In addition to a docking site located between amino acids 30 and 60 of c-Jun, efficient phosphorylation of c-Jun by JNK requires specificity conferring residues located around the phosphoacceptor sites [138]. Most important is proline at the $\mathrm{P}+1$ position, a requirement that is common to JNK and all other MAP kinases ([138] and references therein). In addition, efficient c-Jun phosphorylation by JNK requires a positively charged residue located several amino acids C-terminal to the phosphoacceptor site [138]. While these sequences are absolutely essential for JNKmediated c-Jun phosphorylation, they do not affect the binding of JNK to c-Jun [138]. In addition to ensuring high efficiency of phosphorylation, the c-Jun docking site is responsible for selection of the phosphoacceptor site. Despite the sequence requirements described above, c-Jun contains several potential JNK phosphoacceptor sites. These sites are revealed once docking defective mutants of c-Jun are phosphorylated by JNK in vitro. Although such mutants are inefficiently phosphorylated, phosphopeptide mapping indicates that their phosphorylation occurs on multiple sites while phosphorylation of wild type c-Jun by JNK is restricted to serines 63 and 73 [138]. Collectively these results suggest the following mechanism for JNK-mediated c-Jun phosphorylation. Once JNK is activated it translocates to the nucleus and forms a transient complex with the $\mathrm{N}$-terminal activation domain of c-Jun. The docking of JNK to c-Jun serves to increase the local concentration of the enzyme next to its substrate. Once the initial complex dissociates, JNK interacts with the phosphoacceptor site of c-Jun via its catalytic pocket. This classical form of enzyme-substrate interaction results in c-Jun phosphorylation and dissociation of the enzyme-substrate complex.

In addition to explaining the highly efficient phosphorylation of c-Jun by JNK, this bipartite recognition mechanism explains the specificity of c-Jun phosphorylation. So far, the other subgroups of mammalian MAP kinases were found to be incapable of efficient phosphorylation of serines 63 and 73 of c-Jun. This remarkable substrate specificity stands in contrast to the results of peptide selection experiments. Using an ingenious method based on phosphorylation of a random collection of serine-proline containing peptides [140], Cantley and coworkers found that ERK, JNK and p38 select the same peptide sequence (L. Cantley, personal communication). Thus, the interaction of MAP kinases with the phosphoacceptor peptide, although critical for substrate phosphorylation, does not account for the differences 
in their substrate specificities. The actual specificity of these enzymes is most likely determined by the same mechanism described above for JNK mediated c-Jun phosphorylation.

Of the different Juns, only c-Jun is an efficient JNK substrate. Although JunB contains an effective JNK-docking site similar in its efficiency to the JNK docking site of c-Jun, JunB is not phosphorylated by $\mathrm{JNK}$ at all. The reason is that JunB does not contain prolines at the $\mathrm{P}+1$ position following its equivalents of serines 63 and 73 [138]. Although JunB, like c-Jun, contains cryptic JNK phosphorylation sites, the presence of the efficient docking site localizes the kinase to the N-terminal activation domain of JunB and suppresses its ability to phosphorylate other sites.

Unlike c-Jun and JunB, JunD does not contain an effective JNK docking site. The phosphoacceptor region of JunD, however, is almost identical in its sequence to the phosphoacceptor region of c-Jun, including the prolines at the $\mathrm{P}+1$ positions. Although the phosphorylation of JunD by JNK, measured in vitro or in intact cells, is considerably less efficient than c-Jun phosphorylation, in intact cells, JunD is phosphorylated more efficiently than docking defective mutants of c-Jun [138]. JNK-mediated JunD phosphorylation was found to be facilitated by the heterodimerization of JunD with either c-Jun or JunB, both of which have efficient docking sites. In this case, JNK is first recruited to JunD containing dimers by docking to the partner protein. As in the case of c-Jun, this results in a higher local concentration of JNK, thereby facilitating the phosphorylation of the docking-defective protein in JunD $[101,138]$. In addition to explaining how the JNKs can discriminate between the different Jun proteins, these results illustrate that heterodimerization between transcription factors can affect their targeting by MAP kinases and possibly other signal regulated protein kinases.

\subsection{Other substrates for JNK can contribute to AP-1 activity}

In addition to c-Jun, the JNKs were recently found to phosphorylate and activate other transcription factors. One of these is the transcription factor ATF2 [141-143]. Interestingly, c-Jun and ATF2 dimerize and bind to the non-consensus TRE in the $c$-jun promoter, thereby simulating expression of the $c$-jun gene [144]. The JNK pathway therefore has the potential to regulate both the abundance and activity of c-Jun. JNK can also lead to increased expression of another component of AP-1, c-fos. Like c-jun, $c$-fos is an immediate early gene regulated by several cis-acting elements in its promoter/enhancer region [145]. One of these, the serum response element (SRE), mediates $c$-fos induction in response to many extracellular stimuli including serum growth factors [145]. At least two types of transcription factors bind simultaneously to the SRE; the dimeric serum response factors (SRF) and the ternary complex factors (TCF) $[145,146]$. The best characterized of the TCFs is Elk-1 [147]. Like c-Jun, Elk-1 activity is regulated by phosphorylation [39-41,148]. Phosphorylation of Elk-1 at specific sites in its transactivation domain dramatically stimulates its ability to activate transcription of genes such as c-fos. Growth factor stimulation of the $c$-fos gene was shown to be mediated at least in part by phosphorylation of Elk-1 by the ERKs [39-42]. However, c-fos transcription is also enhanced by other stimuli, such as UV irradiation, IL- 1 and $\mathrm{TNF} \alpha$, and by signaling enzymes such as MEKK, which are poor activators of the ERKs. Mutational analysis has indicated that this activation is dependent on the SRE $[139,149]$. Interestingly, JNK that was immunopurified from UV irradiated cells could phosphorylate recombinant ELK-1 in vitro. In fact, this phosphorylation was as efficient as the phosphorylation by immunopurified activated ERK. Furthermore, the major renaturable ELK-1 kinase in extracts from UV treated cells was found to be JNK [139]. Phosphopeptide mapping and mutational analysis has indicated that JNK phosphorylates ELK-1 on the same major sites as do the ERKs, and that these sites are necessary for stimulating ELK-1's transcriptional activity. [40,139,149,150]. Thus, while induction of the $c$-fos gene by growth factors may be mediated primarily by the ERKs, the JNKs are most likely responsible for $c$-fos induction in response to cellular stresses and cytokines. In both cases, induction of the $c$-fos gene leads to increased production of c-Fos protein, which in turn can translocate to the nucleus and form heterodimers with c-Jun. Increased production of c-Fos is important for AP-1 activity, because Jun/Fos heterodimers are more stable than Jun/Jun homodimers [151], thus leading to a more stable AP1 complex. 


\section{Downstream targets of the P38 and ERK path- ways also contribute to AP-1 activity}

Although it does not phosphorylate or activate c-Jun, p38 can also contribute to AP-1 activity. The specific p38 inhibitor SB203580 [112,152] blocks both $c$-fos and $c$-jun expression in response to UV irradiation and the protein synthesis inhibitor anisomycin [153]. These results should be interpreted carefully, because at higher doses, SB203580 can also block JNK activation. Several other lines of evidence however, support the idea that p38 can contribute to $c$-jun and $c$-fos expression. First, like JNK, p38 can phosphorylate and activate ATF2 $[116,154]$. p38 can thereby contribute to $c$-jun gene induction mediated by the AP-1 binding site in the $c$-jun promoter. In addition to the AP-1 site, the c-jun gene can also be regulated by another cis acting element, which contains a recognition site for MEF2 family of transcription factors. The MEF2 family of transcription factors (consisting of MEF2 A-D) have important roles in mediating c-jun induction by serum [155]. Mutational analysis has shown that the MEF2 site is also critical for induction of the c-Jun promoter by LPS in macrophages, and that this induction requires functional p38 and transcription factor MEF2C. Furthermore, MEF2C was shown to be directly phosphorylated and activated by p38 [156]. Thus, p38 can potentially regulate $c$-Jun transcriptional activity by regulating transcription factors that bind to the AP-1 site as well as the MEF2 site of the $c$-jun promoter.

p38 may also be involved in c-fos induction by several mechanism. Like JNK, p38 can phosphorylate and activate TCF/ELK1 [154], which mediates c-fos induction by binding together with SRF to the SRE. Under some circumstances, c-fos induction also requires another element, however, which is recognized by the transcription factor CREB [157-159]. Recently, p38 was shown to lead to the phosphorylation and activation of CREB. This phosphorylation is mediated by the p38 activated kinase, MAPKAP2 [160]. Finally, the ERKs also appear to have a role in c-fos induction, as they also lead to phosphorylation and activation of can also activate TCF/ELK1 and CREB. While phosphorylation of TCF/ELK1 by ERK appears to be direct [39-42], phosphorylation of CREB is mediated by an ERK activated kinase, RSK2 [46]. The convergence of the various signaling pathways on $c$-jun and $c$-fos are summarized in Fig. 4.

\section{Potential functions of JNK and other MAP kinases}

Although a great deal has been learned about the components of MAP kinase pathways and their orga-
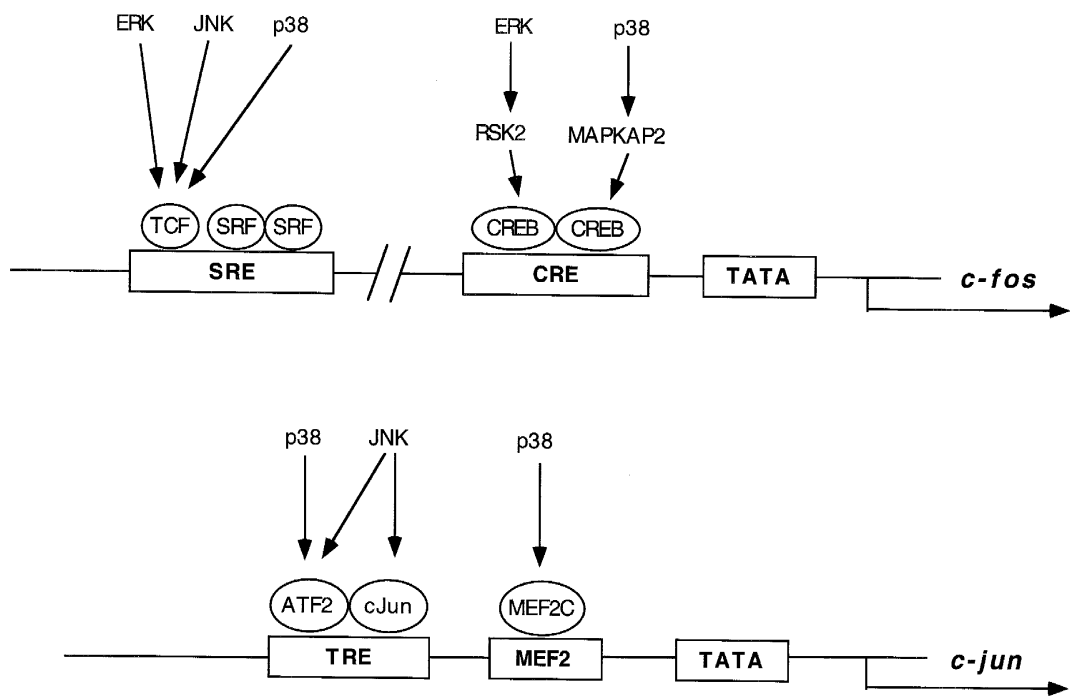

Fig. 4. Transcription of both the $c$-fos and $c$-jun genes are regulated by the three major types of MAP Kinases. All three MAP Kinases activate transcription factors that bind to cis-acting elements in the promoters of these genes. While these promoters contain a number of cis-acting elements, only those that recognize transcription factors that regulated by the ERK, JNK, or p38 MAP Kinases are illustrated. 
nization, much more remains to be learned about the biological functions of MAP kinases, especially in higher eukaryotes. Studying the functions of signal transduction pathways is complicated by the fact that a number of signal transduction pathways are probably activated at any given time in a cell in response to stimulation of a single cell surface receptor. A combination of signaling pathways therefore probably contribute to any given response. Furthermore, the same signaling pathway can often have different functions depending on the cell context. One of the best examples comes from studying the functions of the ERK pathway. While ERK activation has been linked to mitogenic stimulation in fibroblasts, this same signaling pathway can mediate a completely different response in the rat pheochromocytoma cell line, PC12 [161]. In these cells, the ERK pathway mediates a response to NGF, which involves cessation of growth and differentiation into neuron- like cells [161-163]. In addition to cell type, other factors may also determine the functions of MAP kinases. In PC12 cells for example, the decision to proliferate or differentiate may depend on whether the ERK pathway is activated for a transient or a prolonged time period [164].

Although a variety of functions have been attributed to the JNKs, it is difficult to generalize, since their functions are also likely to vary depending on a variety of cellular and environmental conditions. As JNK is activated by a variety of cellular stresses, it has been proposed to serve as a major 'on' switch for programmed cell death [165-168]. In PC12 cells, JNK was proposed to trigger apoptosis in response to nerve growth factor withdrawal, while the ERKs were proposed to inhibit apoptosis. The opposite effect was seen in B cells however. In these cells, activation of the cell surface antigen receptor CD40 activates JNK and rescues cells from apoptosis. Activation of surface $\operatorname{IgM}$ on the other hand stimulates ERK activity and can cause apoptosis. This suggests that in these cells JNK may have the protective role, while ERKs may mediate apoptosis [169]. In fibroblasts and epithelial cells, overexpression of MEKK or ASK1 can both lead to apoptosis $[114,170]$. Since both of these signaling enzymes are strong activators of JNK, it is tempting to speculate that they trigger apoptosis by activating the JNK pathway. However, both of these enzymes can most likely activate other signaling pathways in addition to the JNK or p38 pathways. In fact, over-expression of MEKK was also found to stimulate activity of the c-myc protooncogene, and was shown to stimulate apoptosis by a mechanism that is independent of JNK [170].

$\mathrm{TNF} \alpha$ is a potent activator of the JNK pathway, and can induce apoptosis in some tumor cells. JNK has been proposed to be a major mediator of apoptosis in response to TNF $\alpha$. A catalytically inactive JNKK mutant and a $\mathrm{N}$ terminally truncated c-Jun mutant were shown to block apoptosis by ceramide, a major product of $\mathrm{TNF} \alpha$ activation [166]. It is not clear whether this is a specific effect however, because $\mathrm{TNF} \alpha$ can induce apoptosis in these cells even in the absence of a nucleus, and does not require new protein or RNA synthesis [166]. It is difficult to explain therefore, how c-Jun, a nuclear protein and transcription factor, could mediate apoptosis by $\mathrm{TNF} \alpha$. A more thorough understanding of the mode of action of TNF $\alpha$ has come from analyzing the functions of $\mathrm{TNF} \alpha$ Receptor Interacting proteins. Activated TNFR-1 for example, interacts with the TNFR-1 associated death domain (TRADD) protein. At least three other proteins are then recruited to the TNFR-1-TRADD complex. These include RIP, FADD, and TRAF2. Overexpression of TRAF2 does not stimulate apoptosis, and it is not required for $\mathrm{TNF} \alpha$ induced apoptosis. TRAF2 was shown to be necessary for JNK activation by $\mathrm{TNF} \alpha$ however, and its overexpression is sufficient to stimulate JNK $[51,52]$. RIP also activates the JNKs, but can do so even in the absence of the death domain that causes apoptosis [51]. In contrast, FADD activates the JNKs very inefficiently, but is sufficient to induce apoptosis $[51,52]$. These results indicate that JNK activation and apoptosis in response to $\mathrm{TNF} \alpha$ can be completely separated.

Perhaps the most direct study of the role for the JNK pathway in apoptosis has come from analyzing JNKK (SEK1) null chimaeric mice. Thymocytes from these mice showed significantly increased susceptibility to apoptosis triggered by CD95 (Fas) and CD3 [108]. These results indicate that the JNK pathway may actually confer resistance to apoptosis, rather than triggering apoptosis. Interestingly, JNK activation leading to c-Jun induction most likely mediates a protective function in UV irradiated cells as well (F. Piu and M. Karin, unpublished results). It will be 
interesting to see whether JNK has a protective role against other types of environmental stresses. In addition, studying the mechanism by which the JNK pathway may protect cells from apoptosis and environmental stresses will provide valuable new information about the mechanisms by which cells respond to cellular stresses, and may ultimately provide a means for regulating these responses in various pathological conditions.

The studies summarized above indicate that the potential role for the JNK pathway in apoptosis is still unclear, and probably varies in different cell types. This is not surprising given the fact that the mechanisms governing apoptosis probably vary in different cell types. For example, while in some cells apoptosis can occur even in the absence of de novo protein synthesis [171], in other cells, such as neuronal cells, protein synthesis is required [172]. Thus, the roles for signal transduction pathways leading to transcription factor activation and regulation of gene expression are also likely to vary in these different cell types.

The finding that JNK and p38 are strongly activated by pro-inflammatory cytokines such as $\mathrm{TNF} \alpha$ and IL-1, suggests that these signaling pathways may also have a role in inflammatory responses. Interestingly, both JNK and p38 are also strongly activated in macrophages and monocytes by infectious agents such as the endotoxin LPS, which leads to a potent inflammatory response. Pharmacological inhibitors of p38 block many inflammatory responses, especially the production of cytokines $[112,173,174]$. The promoters of many inflammatory response genes, especially those encoding cytokines and chemokines, have AP-1 binding sites. This suggests a possible role for JNK in their regulation [175]. JNK is also thought to be involved in the induction of cyclooxygenase 2/Prostaglandin Synthase-2, which plays an important role in the inflammatory response by catalyzing the production of prostaglandins [176,177]. More work will be needed to determine whether and how the JNK and p38 pathways can mediate inflammatory responses. A better understanding of these mechanisms will ultimately be important for the development of more specific anti-inflammatory drugs.

JNK is activated not only by cytokines and cellular stresses, but also by stimuli involved in cell growth and proliferation. JNK for example, is strongly acti- vated by onco-proteins such v-Src $[53,177]$, and the JNK pathway may be involved in oncogenic transformation of immortalized fibroblasts by $\mathrm{v}$-Src [177]. More recently JNK activation was suggested to be important for transformation by the Met tyrosine kinase [178]. In many cells JNK is also activated by growth factors [2,53], and in the liver epithelial cell line GN4, the mitogen angiotensin 2 activates JNK very efficiently without exerting much of an effect on ERK activity [97]. Likewise, Rac and Cdc42Hs, which activate the JNK pathway [53-56], also appear to play key roles in cell proliferation, progression through the cell cycle, and oncogenic transformation [179-184]. Many of the guanine nucleotide exchange factors which directly activate these proteins, such as Dbl, Ost, and Tiam, are themselves protooncoproteins [181,184-187], and strongly activate JNK $[53,54]$. It is therefore essential to determine more directly whether JNK activation plays a critical role in mitogenic and oncogenic pathways. Also of interest is whether improper regulation of the JNK pathway can contribute to uncontrolled proliferation and neoplastic transformation.

The biological effects of the JNK pathway probably depend on its cooperation with other signaling pathways. One possibility is that it could cooperate with the ERK pathway to stimulate oncogenic transformation. By using dominant negative mutants, the ERK pathway was shown to be necessary for malignant transformation by oncogenic Ha-RasV12. Likewise, activation of the ERK pathway by overexpressing constitutively active MEK mutants can also transform rodent fibroblasts [35,161]. Recent work has shown, however, that the ERK pathway may not be sufficient for the full transforming effect of Ha-Ras V12 [179,188]. Several studies suggest that signaling pathways mediated by Rho family members including Rac, are necessary for Ha-Ras induced transformation [179,181-183]. Consistent with this, the Rac mediated pathway may synergize with the ERK pathway to produce oncogenic foci in fibroblasts [179]. Since Rac activates JNK and p38, it will be interesting to determine whether this second pathway is the pathway that leads to activation of these MAP kinases. Likewise, it will be interesting to determine whether the JNK or p38 pathways act in concert with the ERK pathway or other signaling pathways to produce a proliferative response. Studies using vari- 
ous effector mutants of Rac, however, indicate that Rac mediated JNK activation can be separated from Rac mediated changes in cell proliferation and transformation and from changes in the organization of the actin cytoskeleton $[189,190]$. These studies suggest that the JNK pathway may not be directly involved in the mitogenic effect of Rac, and that other signaling pathways may mediate proliferation and oncogenic transformation in response to the Rho family of GTP binding proteins.

Studies such as those described above implicate MAP kinase pathways in a variety of cellular responses. The most informative and rigorous analysis of MAP kinase function, however, comes from genetic studies done in other organisms. In the nematode $\mathrm{C}$. elegans, a MAP kinase pathway triggered by the Let23 receptor tyrosine kinase mediates differentiation of vulval precursor cells into mature vulval cells [191]. The inductive signal is the EGF related ligand lin3 [192]. Binding of Lin3 to Let23 stimulates a MAP kinase cascade mediated by the Ras homologue Let60, leading ultimately to activation of the Sur-1/MPK MAP kinases, which are most similar to the mammalian ERKs [193-195]. Mutations in the genes that encode components of this pathway result in either a vulvaless or a multivulval phenotype $[195,196]$.

In Drosophila, several MAP kinase pathways were described. The one most extensively characterized is involved in eye development. Undifferentiated precursor cells in the Drosophila compound eye receive signals from neighboring cells which cause them to differentiate into photoreceptor cells. Neuronal differentiation of the R7 precursor cell is initiated by interaction between the bride of sevenless (BOSS) ligand with the sevenless (SEV) tyrosine kinase receptor. Activation of the receptor by the ligand activates a Ras1 dependent MAP kinase cascade that leads ultimately to activation of the rolled MAPK, which is also most similar to the mammalian ERKs. Rolled phosphorylates various transcription factors necessary for normal eye development. Mutations in genes that encode components of this pathway disrupt normal eye development [197-203].

More recently, a role for JNK has also been described in Drosophila. Drosophila JNK (DJNK) has been shown to be essential for embryonic development. Loss of DJNK inhibits the movement of lateral epithelial cells during mid-embryogenesis, and blocks dorsal closure, processes that involve changes in cell shape and migration [204,205]. In addition to its role in Drosophila development and morphogenesis, DJNK is activated by LPS, which initiates an insect immune response [204]. Thus, in insects as well as mammals, JNK may have a role in mediating immune and inflammatory responses.

In summary, the JNK pathway is activated by a wide range of different types of stimuli. These include not only growth factors, but also proinflammatory cytokines, heat shock, short wavelength UV radiation, and numerous other stimuli. These stimuli elicit very different types of cellular responses, ranging from cell growth to cell death $[109,206]$. It seems likely therefore, that the JNK pathway may have entirely different functions under different conditions. The exact function is likely to be revealed by genetic analysis akin to the studies conducted in yeast, $C$. elegans and D. melanogaster.

\section{Conclusions and future considerations}

A great deal of progress has been made in recent years toward understanding how MAP kinases such as JNK mediate responses to extracellular stimuli. This work has opened up intriguing new questions that need to be addressed in the future. For example, how do cells coordinate responses from different stimuli, and how do they make the decision to activate one signaling pathway over another? Another interesting question is why so many signaling enzymes are members of families of closely related proteins, and how such closely related proteins are specifically activated in response to extracellular stimuli. For example, recent work demonstrated the existence of multiple MEKKs [65] and PAKs [55,7275]. Do these enzymes simply have redundant functions, or do they have distinct functions, such as mediating and integrating responses from different extracellular stimuli? Other questions relate to the specific functions of signaling pathways. As mentioned above, different signaling pathways can probably act together to some extent. In some cases one pathway can even activate another by an autocrine loop mechanism [60], but in other cases one pathway may negatively regulate the other. For example, acti- 
vation of cyclic AMP (cAMP)-dependent protein kinase A (PKA) can downregulate the ERK pathway by inhibiting Raf activity. This inhibition weakens Raf-1 interaction with Ras and may also directly inhibit Raf-1 activity by phosphorylation of its kinase domain [207-213]. It will be important to determine how different signaling pathways interact with each other in order to mediate and coordinate specific biological responses. One way that signaling pathways could affect one another could be by induction of specific phosphatases. Recently, several phosphatases of the MKP family were found to specifically dephosphorylate JNK on threonine and tyrosine residues, thereby inhibiting its activity [101,214,215]. Since transcription of the genes encoding these phosphatases may be regulated by an ERK dependent pathway, their induction may provide a mechanism by which one pathway can regulate another [214]. Another important area of investigation is the identification of target genes whose expression is regulated by MAP kinases. Identification of such target genes should provide important new information about the biological responses that are activated by the MAP Kinases. In addition, it will be of extreme importance to determine how MAP kinases regulate steps other than transcription initiation in the overall process of gene expression, such as mRNA stability and translational efficiency [216]. Finally, the biological functions of specific signaling pathways need to be investigated further. When studying the functions of various signal transduction pathways including the JNK pathway, it will be important to consider the possible contributions of various factors. These include cell type, the type of stimulus, the duration and magnitude of the response, and the activation of other signaling pathways in the cell.

\section{References}

[1] C.J. Marshall, Curr Opin Genet Dev 4 (1994) 82-89.

[2] E. Cano, L.C. Mahadevan, Trends Biochem Sci 20 (1995) $117-122$.

[3] A.J. Waskiewicz, J.A. Cooper, Curr Opin Cell Biol 7 (1995) 798-805.

[4] M. Karin, Philos. Trans. R. Soc. Lond. B Biol. Sci. 351 (1996) 127-134.
[5] M.H. Cobb, T.G. Boulton, D.J. Robbins, Cell Regul. 2 (1991) 965-978.

[6] M. Hibi, A. Lin, T. Smeal, A. Minden, M. Karin, Genes Dev 7 (1993) 2135-2148.

[7] B. Derijard, M. Hibi, I.H. Wu, T. Barrett, B. Su, T. Deng, M. Karin, R.J. Davis, Cell 76 (1994) 1025-1037.

[8] J.M. Kyriakis, P. Banerjee, E. Nikolakaki, T. Dai, E.A. Rubie, D.M.F. Ahma, J. Avruch, J.R. Woodgett, Nature 369 (1994) 156-160.

[9] J. Han, J.D. Lee, L. Bibbs, R.J. Ulevitch, Science 265 (1994) 808-811.

[10] J. Rouse, P. Cohen, S. Trigon, M. Morange, S.A. AlonsoLlamazare, D. Zamanillo, T. Hunt, A.R. Nebreda, Cell 78 (1994) 1027-1037.

[11] M. Cheng, T.G. Boulton, M.H. Cobb, J Biol Chem 271 (1996) 8951-8958.

[12] G. Zhou, Z.Q. Bao, J.E. Dixon, J Biol Chem 270 (1995) $12665-12669$.

[13] A.S. Zervos, L. Faccio, J.P. Gatto, J.M. Kyriakis, R. Brent, Proc Natl Acad Sci USA. 92 (1995) 10531-10534.

[14] C. Lechner, M.A. Zahalka, J.F. Giot, N.P. Moller, A. Ullrich, Proc Natl Acad Sci USA. 93 (1996) 4355-4359.

[15] S. Mertens, M. Craxton, FEBS Lett. 383 (1996) 273-276.

[16] Y. Jiang, C. Chen, Z. Li, W. Guo, J.A. Gegner, S. Lin, J. Han, J Biol Chem 271 (1996) 17920-17926.

[17] I. Herskowitz, Cell 80 (1995) 187-197.

[18] D.E. Levin, B. Errede, Curr. Opin. Cell. Biol 7 (1995) 197-202.

[19] M. Whiteway, B. Errede, in: R.P. Dottin, J. Kurjan, B.L. Taylor, Orlando (Eds.), Molecular Mechanisms of Signal Transduction in Genetically Tractable Organisms, Academic Press, 1994, pp. 187-236.

[20] K.S. Lee, K. Irie, Y. Gotoh, Y. Watanabe, H. Araki, E. Nishida, K. Matsumoto, D.E. Levin, Mol Cell Biol 13 (1993) 3067-3075.

[21] J.L. Brewster, T. de Valoir, N.D. Dwyer, E. Winter, M.C. Gustin, Science 259 (1993) 1760-1763.

[22] K.Y. Choi, B. Satterberg, D.M. Lyons, E.A. Elion, Cell 78 (1994) 499-512.

[23] M.S. Whiteway, C. Wu, T. Leeuw, K. Clark, A. FourestLieuvin, D.Y. Thomas, E. Leberer, Science 269 (1995) 1572-1575.

[24] E. Leberer, D. Dignard, D. Harcus, D. Thomas, M. Whiteway, EMBO J 11 (1992) 4815-4824.

[25] E. Leberer, D. Dignard, D. Harcus, L. Hougan, M. Whiteway, D.Y. Thomas, Mol Gen Genet. 241 (1993) 241-254.

[26] D.L. Cadena, G.N. Gill, FASEB J 6 (1992) 2332-2337.

[27] J. Schlessinger, Curr Opin Genet Dev 4 (1994) 25-30.

[28] A. Aronheim, D. Engelberg, N. Li, N. al-Alawi, J. Schlessinger, M. Karin, Cell 78 (1994) 949-961.

[29] P. Chardin, J.H. Camonis, N.W. Gale, L. van Aelst, J. Schlessinger, M.H. Wigler, D. Bar-Sagi, Science 260 (1993) 1338-1343.

[30] N.W. Gale, S. Kaplan, E.J. Lowenstein, J. Schlessinger, D. Bar-Sagi, Nature 363 (1993) 88-92. 
[31] R. Marais, Y. Light, H.F. Paterson, C.J. Marshall, EMBO J 14 (1995) 3136-3145.

[32] A.B. Vojtek, S.M. Hollenberg, J.A. Cooper, Cell 74 (1993) 205-214.

[33] P. Dent, W. Haser, T.A. Haystead, L.A. Vincent, T.M. Roberts, T.W. Sturgill, Science 257 (1992) 1404-1407.

[34] J.M. Kyriakis, H. App, X.F. Zhang, P. Banerjee, D.L. Brautigan, U.R. Rapp, J. Avruch, Nature 358 (1992) 417421.

[35] S.J. Mansour, W.T. Matten, A.S. Hermann, J.M. Candia, S. Rong, K. Fukasawa, G.F. Vande Woude, N.G. Ahn, Science 265 (1994) 966-970.

[36] M.H. Cobb, J.E. Hepler, M. Cheng, D. Robbins, Semin Cancer Biol. 5 (1994) 261-268.

[37] J. Posada, N. Yew, N.G. Ahn, G.F. Vande Woude, J.A. Cooper, Mol Cell Biol. 13 (1993) 2546-2553.

[38] N.G. Ahn, R. Seger, E.G. Krebs, Curr Opin Cell Biol 4 (1992) 992-999.

[39] R. Marais, J. Wynne, R. Treisman, Cell 73 (1993) 381-393.

[40] H. Gille, M. Kortenjann, O. Thomae, C. Moomaw, C. Slaughter, M.H. Cobb, P.E. Shaw, EMBO J 14 (1995) 951-962.

[41] H. Gille, A.D. Sharrocks, P.E. Shaw, Nature 358 (1992) 414-417.

[42] R. Zinck, R.A. Hipskind, V. Pingoud, A. Nordheim, Embo. J. 12 (1993) 2377-2387.

[43] R. Janknecht, W.H. Ernst, A. Nordheim, Oncogene 10 (1995) 1209-1216.

[44] P. Coffer, M. de Jonge, A. Mettouchi, B. Binetruy, J. Ghysdael, W. Kruijer, Oncogene 9 (1994) 911-921.

[45] B.S. Yang, C.A. Hauser, G. Henkel, M.S. Colman, C. Van Beveren, K.J. Stacey, D.A. Hume, A.A. Maki, M.C. Ostrowski, Mol. Cel. Biol 16 (1996) 538-547.

[46] J. Xing, D.D. Ginty, M.E. Greenberg, Science 273 (1996) 959-963.

[47] A. Minden, A. Lin, T. Smeal, B. Derijard, M. Cobb, R. Davis, M. Karin, Mol Cell Biol 14 (1994) 6683-6688.

[48] T. Kallunki, B. Su, I. Tsigelny, H.K. Sluss, B. Derijard, G. Moore, R. Davis, M. Karin, Genes Dev. 8 (1994) 29963007.

[49] H.K. Sluss, T. Barrett, B. Derijard, R.J. Davis, Mol Cell Biol 14 (1994) 8376-8384.

[50] S.J. Baker, E.P. Reddy, Oncogene 12 (1996) 1-9.

[51] Z.G. Liu, H. Hsu, D.V. Goeddel, M. Karin, Cell 87 (1996) 565-576.

[52] G. Natoli, A. Costanzo, A. Ianni, D.J. Templeton, J.R. Woodgett, C. Balsano, M. Levrero, Science 275 (1997) 200-203.

[53] A. Minden, A. Lin, F.X. Claret, A. Abo, M. Karin, Cell 81 (1995) 1147-1157.

[54] O.A. Coso, M. Chiariello, J.C. Yu, H. Teramoto, P. Crespo, N. Xu, T. Miki, J.S. Gutkind, Cell 81 (1995) 11371146.

[55] J.L. Brown, L. Stowers, M. Baer, J. Trejo, S. Coughlin, J. Chant, Curr Biol 6 (1996) 598-605.
[56] S. Bagrodia, B. Derijard, R.J. Davis, R.A. Cerione, J Biol Chem 270 (1995) 27995-27998.

[57] A.J. Ridley, H.F. Paterson, C.L. Johnston, D. Diekmann, A. Hall, Cell 70 (1992) 401-410.

[58] R. Kozma, S. Ahmed, A. Best, L. Lim, Mol Cell Biol 15 (1995) 1942-1952.

[59] C.D. Nobes, A. Hall, Cell 81 (1995) 53-62.

[60] A. Minden, A. Lin, M. McMahon, C. Lange-Carter, B. Derijard, R.J. Davis, G.L. Johnson, M. Karin, Science 266 (1994) 1719-1723.

[61] T.A. Bird, J.M. Kyriakis, L. Tyshler, M. Gayle, A. Milne, G.D. Virca, J Biol Chem 269 (1994) 31836-31844.

[62] M. Yan, T. Dai, J.C. Deak, J.M. Kyriakis, L.I. Zon, J.R. Woodgett, Nature 372 (1994) 798-800.

[63] S. Xu, D.J. Robbins, L.B. Christerson, J.M. English, C.A. Vanderbilt, M.H. Cobb, Proc Natl Acad Sci USA 93 (1996) 5291-5295.

[64] C.A. Lange-Carter, C.M. Pleiman, A.M. Gardner, K.J. Blumer, G.L. Johnson, Science 260 (1993) 315-319.

[65] J.L. Blank, P. Gerwins, E.M. Elliott, S. Sather, G.L. Johnson, J Biol Chem 271 (1996) 5361-5368.

[66] A. Salmeron, T.B. Ahmad, G.W. Carlile, D. Pappin, R.P. Narsimhan, S.C. Ley, EMBO J 15 (1996) 817-826.

[67] A. Lin, A. Minden, H. Martinetto, F.X. Claret, C. LangeCarter, F. Mercurio, G.L. Johnson, M. Karin, Science 268 (1995) 286-290.

[68] I. Sanchez, R.T. Hughes, B.J. Mayer, K. Yee, J.R. Woodgett, J. Avruch, J.M. Kyriakis, L.I. Zon, Nature 372 (1994) 794-798.

[69] B. Derijard, J. Raingeaud, T. Barrett, I.H. Wu, J. Han, R.J. Ulevitch, R.J. Davis, Science 267 (1995) 682-685.

[70] G. Boguslawski, J.O. Polazzi, Proc Natl Acad Sci USA 84 (1987) 5848-5852.

[71] Z. Galcheva-Gargova, B. Derijard, I.H. Wu, R.J. Davis, Science 265 (1994) 806-808.

[72] G.A. Martin, G. Bollag, F. McCormick, A. Abo, EMBO J 14 (1995) 1970-1978.

[73] E. Manser, T. Leung, H. Salihuddin, Z.S. Zhao, L. Lim, Nature 367 (1994) 40-46.

[74] E. Manser, C. Chong, Z.S. Zhao, T. Leung, G. Michael, C. Hall, L. Lim, J Biol Chem 270 (1995) 25070-25078.

[75] M. Teo, E. Manser, L. Lim, J Biol Chem 270 (1995) 26690-26697.

[76] A.E. Adams, D.I. Johnson, R.M. Longnecker, B.F. Sloat, J.R. Pringle, J Cell Biol 111 (1990) 131-142.

[77] Z.S. Zhao, T. Leung, E. Manser, L. Lim, Mol Cell Biol 15 (1995) 5246-5257.

[78] S. Zhang, J. Han, M.A. Sells, J. Chernoff, U.G. Knaus, R.J. Ulevitch, G.M. Bokoch, J Biol Chem 270 (1995) 23934-23936.

[79] P. Katz, G. Whalen, J.H. Kehrl, J Biol Chem 269 (1994) 16802-16809.

[80] C.M. Pombo, J.H. Kehrl, I. Sanchez, P. Katz, J. Avruch, L.I. Zon, J.R. Woodgett, T. Force, J.M. Kyriakis, Nature 377 (1995) 750-754. 
[81] R.M. Tung, J. Blenis, Oncogene 14 (1997) 653-659.

[82] M.C. Hu, W.R. Qiu, G.X. Wan, C.F. Meyer, T.H. Tan, Genes Dev 10 (1996) 2251-2264.

[83] Y.-C. Su, J. Han, S. Xu, M. Cobb, E.Y. Skolnik, EMBO J. 16 (1997) 1279-1290.

[84] Y.L. Ing, I.W. Leung, H.H. Heng, L.C. Tsui, N.J. Lassam, Oncogene 9 (1994) 1745-1750.

[85] A. Rana, K. Gallo, P. Godowski, S. Hirai, S. Ohno, L. Zon, J.M. Kyriakis, J. Avruch, J Biol Chem 271 (1996) 19025-19028.

[86] L.A. Tibbles, Y.L. Ing, F. Kiefer, J. Chan, N. Iscove, J.R. Woodgett, N.J. Lassam, EMBO J 15 (1996) 7026-7035.

[87] H. Teramoto, O.A. Coso, H. Miyata, T. Igishi, T. Miki, J.S. Gutkind, J Biol Chem 271 (1996) 27225-227228.

[88] S. Hirai, M. Izawa, S. Osada, G. Spyrou, S. Ohno, Oncogene 12 (1996) 641-650.

[89] T. Kodaki, R. Woscholski, B. Hallberg, P. RodriguezViciana, J. Downward, P.J. Parker, Curr Biol 4 (1994) 798-806.

[90] P. Rodriguez-Viciana, P.H. Warne, R.B.V. Dhand, I. Gout, M.J. Fry, M. Waterfield, D.J. Downwar, Nature 370 (1994) 527-532.

[91] P. Rodriguez-Viciana, P.H. Warne, B. Vanhaesebroeck, M.D. Waterfield, J. Downward, EMBO J 15 (1996) 24422451.

[92] K. Rei, C.D. Nobes, G. Thomas, A. Hall, D.A. Cantrell, Curr Biol. 6 (1996) 1445-1455.

[93] A. Klippel, C. Reinhard, W.M. Kavanaugh, G. Apell, M.A. Escobedo, L.T. Williams, Mol Cell Biol 16 (1996) 41174127.

[94] O.A. Coso, M. Chiariello, G. Kalinec, J.M. Kyriakis, J. Woodgett, J.S. Gutkind, J Biol Chem 270 (1995) 56205624.

[95] O.A. Coso, H. Teramoto, W.F. Simonds, J.S. Gutkind, J Biol Chem 271 (1996) 3963-3966.

[96] F.M. Mitchell, M. Russell, G.L. Johnson, Biochem J 309 (1995) 381-384.

[97] I.E. Zohn, H. Yu, X. Li, A.D. Cox, H.S. Earp, Mol Cell Biol 15 (1995) 6160-6168.

[98] L.R. Collins, A. Minden, M. Karin, J.H. Brown, J Biol Chem 271 (1996) 17349-17353.

[99] L.E. Heasley, B. Storey, G.R. Fanger, L. Butterfield, J. Zamarripa, D. Blumberg, R.A. Maue, Mol Cell Biol 16 (1996) 648-656.

[100] M.V. Prasad, J.M. Dermott, L.E. Heasley, G.L. Johnson, N. Dhanasekaran, J Biol Chem 270 (1995) 18655-18659.

[101] S. Gupta, T. Barrett, A.J. Whitmarsh, J. Cavanagh, H.K. Sluss, B. Derijard, R.J. Davis, EMBO J 15 (1996) 27602770.

[102] S. Matsuda, H. Kawasaki, T. Moriguchi, Y. Gotoh, E. Nishida, J Biol Chem 270 (1995) 12781-12786.

[103] V. Adler, A. Schaffer, J.L.D. Kim, Z. Ronai, J Biol Chem 270 (1995) 26071-26077.

[104] S. Kharbanda, P. Pandey, R. Ren, B. Mayer, L. Zon, D. Kufe, J Biol Chem 270 (1995) 30278-30281.

[105] S. Kharbanda, R. Ren, P. Pandey, T.D. Shafman, S.M.
Feller, R.R. Weichselbaum, D.W. Kufe, Nature 376 (1995) 785-788.

[106] C. Rosette, M. Karin, Science 274 (1996) 1194-1197.

[107] Y. Devary, C. Rosette, J.A. DiDonato, M. Karin, Science 261 (1993) 1442-1445.

[108] H. Nishina, K.D. Fischer, L. Radvanyi, A. Shahinian, R. Hakem, E.A. Rubie, A. Bernstein, T.W. Mak, J.R. Woodgett, J.M. Penninger, Nature 385 (1997) 350-353.

[109] Z.G. Liu, R. Baskaran, E.T. Lea-Chou, L.D. Wood, Y. Chen, M. Karin, J.Y. Wang, Nature 384 (1996) 273-276.

[110] G. Tokiwa, I. Dikic, S. Lev, J. Schlessinger, Science 273 (1996) 792-794.

[111] S. Lev, H. Moreno, R. Martinez, P. Canoll, E. Peles, J.M. Musacchio, Nature 376 (1995) 737-745.

[112] J.C. Lee, J.T. Laydon, P.C. McDonnel, T.F. Gallagher, S. Kumar, D. Green, D. McNulty, M.J. Blumenthal, J.R. Heys, S.W. Landvatter, J.E. Strickler, M.M. McLaughlin, I.R. Siemens, S. Fisher, G. Livi, J. White, J.L. Adams, P.R. Young, Nature 372 (1994) 739-746.

[113] J.M. Kyriakis, J. Avruch, Bioessays 18 (1996) 567-577.

[114] H. Ichijo, E. Nishida, K. Irie, P.M.S. ten Dijke, T. Moriguchi, M. Takagi, K. Matsumoto, K. Miyazono, Y. Gotoh, Science 275 (1997) 90-94.

[115] J. Han, J.D. Lee, Y. Jiang, Z. Li, L. Feng, R.J. Ulevitch, J Biol Chem 271 (1996) 2886-2891.

[116] J. Raingeaud, A.J. Whitmarsh, T. Barrett, B. Derijard, R. Davis, Mol Cell Biol 16 (1996) 1247-1255.

[117] P. Angel, M. Karin, Biochim Biophys Acta 1072 (1991) 129-157.

[118] R. Chiu, P. Angel, M. Karin, Cell 59 (1989) 979-986.

[119] R.S. Johnson, B. van Lingen, V.E. Papaioannou, B.M. Spiegelman, Genes Dev 7 (1993) 1309-1317.

[120] F. Hilberg, A. Aguzzi, N. Howells, E.F. Wagner, Nature 365 (1993) 179-181.

[121] R.S. Johnson, B.M. Spiegelman, V. Papaioannou, Cell 71 (1992) 577-586.

[122] B. Wasylyk, C. Wasylyk, P. Flores, A. Begue, D. Leprince, D. Stehelin, Nature 346 (1990) 191-193.

[123] B. Stein, A.S. Baldwin Jr, D.W. Ballard, W.C. Greene, P. Angel, P. Herrlich, EMBO J 12 (1993) 3879-3891.

[124] F.X. Claret, M. Hibi, S. Dhut, T. Toda, M. Karin, Nature 383 (1996) 453-457.

[125] K. Ryder, L.F. Lau, D. Nathans, Proc Natl Acad Sci USA 85 (1988) 1487-1491.

[126] K. Ryder, A. Lanahan, E. Perez-Albuerne, D. Nathans, Proc Natl Acad Sci USA 86 (1989) 1500-1503.

[127] P. Angel, K. Hattori, T. Smeal, M. Karin, Cell 55 (1988) 875-885.

[128] Y. Devary, R.A. Gottlieb, L.F. Lau, M. Karin, Mol Cell Biol 11 (1991) 2804-2811.

[129] W.W. Lamph, P. Wamsley, P. Sassone-Corsi, I.M. Verma, Nature 334 (1988) 629-631.

[130] D.A. Brenner, M. O'Hara, P. Angel, M. Chojkier, M. Karin, Nature 337 (1989) 661-663.

[131] T. Smeal, B. Binetruy, D.A. Mercola, M. Birrer, M. Karin, Nature 354 (1991) 494-496. 
[132] B.J. Pulverer, J.M. Kyriakis, J. Avruch, E. Nikolakaki, J.R. Woodgett, Nature 353 (1991) 670-674.

[133] T. Smeal, B. Binetruy, D. Mercola, A. Grover-Bardwick, G. Heidecker, U.R. Rapp, M. Karin, Mol Cell Biol 12 (1992) 3507-3513.

[134] A.M. Musti, M. Treier, D. Bohmann, Science 275 (1997) 400-402.

[135] A. Lin, J. Frost, T. Deng, T. Smeal, N. al-Alawi, U. Kikkawa, T. Hunter, D. Brenner, M. Karin, Cell 70 (1992) 777-789.

[136] T. Smeal, M. Hibi, M. Karin, EMBO J 13 (1994) 60066010.

[137] A.J. Bannister, T. Oehler, D. Wilhelm, P. Angel, T. Kouzarides, Oncogene 11 (1995) 2509-2514.

[138] T. Kallunki, T. Deng, M. Hibi, M. Karin, Cell 87 (1996) 929-939.

[139] M. Cavigelli, F. Dolfi, F.X. Claret, M. Karin, EMBO J 14 (1995) 5957-5964.

[140] Z. Songyang, S. Blechner, N. Hoagland, M.F. Hoekstra, H. Piwnica-Worms, L.C. Cantley, Curr. Biol. 4 (1994) 973982.

[141] S. Gupta, D. Campbell, B. Derijard, R.J. Davis, Science 267 (1995) 389-393.

[142] C. Livingstone, G. Patel, N. Jones, EMBO J. 14 (1995) 1785-1797.

[143] H. van Dam, D. Wilhelm, I. Herr, A. Steffen, P. Herrlich, P. Angel, EMBO J 14 (1995) 1798-1811.

[144] H. van Dam, M. Duyndam, R. Rottier, A. Bosch, L. de Vries-Smits, P. Herrlich, A. Zantema, P. Angel, A.J. van der Eb, EMBO J 12 (1993) 479-487.

[145] R. Treisman, Trends Biochem. Sci 17 (1992) 423-426.

[146] R. Treisman, Curr. Opin. Genet. Dev 4 (1994) 96-107.

[147] R.A. Hipskind, V.N. Rao, C.G. Mueller, E.S. Reddy, A. Nordheim, Nature 354 (1991) 531-534.

[148] C.S. Hill, R. Marais, S. John, J. Wynne, S. Dalton, R. Treisman, Cell 73 (1993) 395-406.

[149] A.J. Whitmarsh, P. Shore, A.D. Sharrocks, R.J. Davis, Science 269 (1995) 403-407.

[150] R. Zinck, M.A. Cahill, M. Kracht, C. Sachsenmaier, R.A. Hipskind, A. Nordheim, Mol. Cell. Biol. 15 (1995) 49304938.

[151] T. Smeal, P. Angel, J. Meek, M. Karin, Genes Dev 3 (1989) 2091-2100.

[152] A. Cuenda, J.Y.N.D. Rouse, R. Meier, P. Cohen, T.F. Gallagher, P.R. Young, J.C. Lee, FEBS Lett 364 (1995) 229-233.

[153] C.A. Hazzalin, E. Cano, A. Cuenda, M.J. Barratt, P. Cohen, L.C. Mahadevan, Curr Biol 6 (1996) 1028-1031.

[154] M.A. Price, F.H. Cruzalegui, R. Treisman, EMBO J 15 (1996) 6552-6563.

[155] T.H. Han, R. Prywes, Mol Cell Biol 15 (1995) 2907-2915.

[156] J. Han, Y. Jiang, Z. Li, V.V. Kravchenko, R.J. Ulevitch, Nature 386 (1997) 296-299.

[157] A. Bonni, D.D. Ginty, H. Dudek, M.E. Greenberg, Mol Cell Neurosci 6 (1995) 168-183.
[158] D.D. Ginty, A. Bonni, M.E. Greenberg, Cell 77 (1994) 713-725.

[159] L.A. Berkowitz, K.T. Riabowol, M.Z. Gilman, Mol Cell Biol 9 (1989) 4272-4281.

[160] Y. Tan, J. Rouse, A. Zhang, S. Cariati, P. Cohen, M.J. Comb, EMBO J 15 (1996) 4629-4642.

[161] S. Cowley, H. Paterson, P. Kemp, C.J. Marshall, Cell 77 (1994) 841-852.

[162] L.A. Greene, A.S. Tischler, Proc Natl Acad Sci USA. 73 (1976) 2424-2428.

[163] K.W. Wood, H. Qi, G. D’Arcangelo, R.C. Armstrong, T.M. Roberts, S. Halegoua, Proc. Nat. Acad. Sci USA 90 (1993) 5016-5020.

[164] S. Traverse, N. Gomez, H. Paterson, C. Marshall, P. Cohen, Biochem J 288 (1992) 351-355.

[165] Y.R. Chen, C.F. Meyer, T.H. Tan, J Biol Chem 27 (1996) 631-634.

[166] M. Verheij, R. Bose, X.H. Lin, B. Yao, W.D. Jarvis, S. Grant, M.J. Birrer, E. Szabo, L.I. Zon, J.M. Kyriakis, A. Haimovitz-Friedman, Z. Fuks, R.N. Kolesnick, Nature 380 (1996) 75-79.

[167] D.J. Wilson, K.A. Fortner, D.H. Lynch, R.R. Mattingly, I.G. Macara, J.A. Posada, R.C. Budd, Eur J Immunol 26 (1996) 989-994.

[168] Z. Xia, M. Dickens, J. Raingeaud, R.J. Davis, M.E. Greenberg, Science 270 (1995) 1326-1331.

[169] N. Sakata, H.R. Patel, N. Terada, A. Aruffo, G.L. Johnson, E.W. Gelfand, J Biol Chem 270 (1995) 30823-30828.

[170] N.L. Johnson, A.M. Gardner, K.M. Diener, C.A. LangeCarter, J. Gleavy, M.B. Jarpe, A. Minden, M. Karin, L.I. Zon, G.L. Johnson, J Biol Chem 271 (1996) 3229-3237.

[171] S.J. Martin, Immunol Lett. 35 (1993) 125-134.

[172] E.M.J. Johnson, T.L. Deckwerth, Annu Rev Neurosci. 16 (1993) 31-46.

[173] J.C. Lee, P.R. Young, J Leukoc Biol 59 (1996) 152-157.

[174] R. Beyaert, A. Cuenda, W. Vanden Berghe, S. Plaisance, J.C. Lee, G. Haegeman, P. Cohen, W. Fiers, EMBO J 15 (1996) 1914-1923.

[175] J. Saklatvala, W. Davis, F. Guesdon, Philos. Trans. R. Soc. Lond. B Biol. Sci. 351 (1996) 151-157.

[176] H.R. Herschman, Biochim Biophys Acta. 1299 (1996) 125-140.

[177] W. Xie, H.R. Herschman, J. Biol. Chem. 270 (1995) 27622-27628.

[178] Rodriguez et al., EMBO J. (1997) in press.

[179] R.G. Qiu, J. Chen, D. Kirn, F. McCormick, Nature 374 (1995) 457-459.

[180] M.F.A.A. Olson, A. Hall, Science 269 (1995) 1270-1272.

[181] F.N. van Leeuwen, R.A. van der Kammen, G.G. Habets, J.G. Collard, Oncogene 11 (1995) 2215-2221.

[182] R.G. Qiu, J. Chen, F. McCormick, M. Symons, Proc Natl Acad Sci USA 92 (1995) 11781-11785.

[183] G.C. Prendergast, R. Khosravi-Far, P.A. Solski, H. Kurzawa, P. Lebowitz, C.J. Der, Oncogene 10 (1995) 2289-2296. 
[184] F. Michiels, G.G. Habets, J.C. Stam, R.A. van der Kammen, J.G. Collard, Nature 375 (1995) 338-340.

[185] L.A. Quilliam, R. Khosravi-Far, S.Y. Huff, C.J. Der, Bioessays 17 (1995) 395-404.

[186] R. Khosravi-Far, M. Chrzanowska-Wodnicka, P.A. Solski, A. Eva, K. Burridge, C.J. Der, Mol Cell Biol 14 (1994) 6848-6857.

[187] Y. Horii, J.F. Beeler, K. Sakaguchi, M. Tachibana, T. Miki, EMBO J 13 (1994) 4776-4786.

[188] M.A. White, C. Nicolette, A. Minden, A. Polverino, L. Van Aelst, M. Karin, M.H. Wigler, Cell 80 (1995) 533541.

[189] T. Joneson, M. McDonough, D. Bar-Sagi, L. Van Aelst, Science 274 (1996) 1374-1376.

[190] N. Lamarche, N. Tapon, L. Stowers, P.D. Burbelo, P. Aspenstrom, T. Bridges, J. Chant, A. Hall, Cell 87 (1996) 519-529.

[191] R.V. Aroian, M. Koga, J.E.Y.O. Mendel, P.W. Sternberg, Nature 348 (1990) 693-699.

[192] R.J. Hill, P.W. Sternberg, Nature 358 (1992) 470-476.

[193] M.R. Lackner, K. Kornfeld, L.M. Miller, H.R. Horvitz, S.K. Kim, Genes Dev 8 (1994) 160-173.

[194] Y. Wu, M. Han, Genes Dev 8 (1994) 147-159.

[195] P.S. Kayne, P.W. Sternberg, Curr. Opin. Genet. Dev. 5 (1995) 38-43.

[196] H.R. Horvitz, P.W. Sternberg, Nature 351 (1991) 535-541.

[197] M.A. Simon, D.D. Bowtell, G.S. Dodson, T.R. Laverty, G.M. Rubin, Cell 67 (1991) 701-716.

[198] S.L. Zipursky, G.M. Rubin, Annu Rev Neurosci. 17 (1994) 373-397.

[199] R.D. Rogge, C.A. Karlovich, U. Banerjee, Cell 64 (1991) 39-48.

[200] M.E. Fortini, M.A. Simon, G.M. Rubin, Nature 355 (1992) 497-498.

[201] W.H. Biggs 3rd, K.H. Zavitz, B. Dickson, A. van der
Straten, D. Brunner, E. Hafen, S.L. Zipursky, EMBO J 13 (1994) 1628-1635.

[202] D. Brunner, N. Oellers, J. Szabad, W.H. Biggs 3rdd, S.L. Zipursky, E. Hafen, Cell 76 (1994) 875-888.

[203] D.A. Wassarman, M. Therrien, G.M. Rubin, Curr Opin Genet Dev 5 (1995) 44-50.

[204] H.K. Sluss, Z. Han, T. Barrett, R.J. Davis, Y.T. Ip, Genes Dev 10 (1996) 2745-2758.

[205] J.R. Riesgo-Escovar, M. Jenni, A. Fritz, E. Hafen, Genes Dev 10 (1996) 2759-2768.

[206] C.E. Canman, M.B. Kastan, Nature 384 (1996) 213-214.

[207] S. Hafner, H.S. Adler, H. Mischak, P. Janosch, G. Heidecker, A. Wolfman, S. Pippig, M. Lohse, M. Ueffing, W. Kolch, Mol Cell Biol 14 (1994) 6696-6703.

[208] B.M. Burgering, G.J. Pronk, P.C.P.C. van Weeren, J.L. Bos, EMBO J 12 (1993) 4211-4220.

[209] L.M. Graves, K.E. Bornfeldt, E.W. Raines, B.C. Potts, S.G. Macdonald, R. Ross, E.G. Krebs, Proc. Natl. Acad. Sci. USA. 90 (1993) 10300-10304.

[210] P.L.I.V. Hordijk, E.J. van Corven, W.H. Moolenaar, J. Biol. Chem. 269 (1994) 645-651.

[211] M. Russell, S. Winitz, G.L. Johnson, Mol Cell Biol 14 (1994) 2343-2351.

[212] B.R. Sevetson, X. Kong, J.C., L.J., Proc. Natl. Acad. Sci. USA 90 (1993) 10305-10309.

[213] J. Wu, P. Dent, T. Jelinek, A. Wolfman, M.J. Weber, T.W. Sturgill, Science 262 (1993) 988-990.

[214] D.D. Hirsch, P.J. Stork, J Biol Chem. 272 (1997) 45684575.

[215] Y. Liu, M. Gorospe, C. Yang, N.J. Holbrook, J Biol Chem. 270 (1995) 8377-8380.

[216] T.A. Lin, X. Kong, T.A. Haystead, A. Pause, G. Belsham, N. Sonenberg, J.J.C. Lawrence, Science 266 (1994) 542543. 